\title{
Catabolite Inactivation of the Glucose Transport System in Saccharomyces cerevisiae
}

\author{
By ANA BUSTURIA AND ROSARIO LAGUNAS* \\ Instituto de Investigaciones Biomédicas del CSIC, Facultad de Medicina de la UAM, \\ Arzobispo Morcillo 4, 28029 Madrid, Spain
}

(Received 2 July 1985; revised 17 September 1985)

\begin{abstract}
The sugar transport systems of Saccharomyces cerevisiae are irreversibly inactivated when protein synthesis is inhibited. This inactivation is responsible for the drastic decrease in fermentation observed in ammonium-starved yeast and is related to the occurrence of the Pasteur effect in these cells. Our study of the inactivation of the glucose transport system indicates that both the high-affinity and the low-affinity components of this system are inactivated. Inactivation of the high-affinity component evidently requires the utilization of a fermentable substrate by the cells, since (i) inactivation did not occur during carbon starvation, (ii) when a fermentable sugar was added to starved cells, inactivation began, (iii) when the fermentation inhibitors iodoacetate or arsenate were added in addition to sugars, the inactivation was prevented, (iv) when a non-fermentable substrate was added instead of sugars, inactivation was also prevented. The inactivation of the low-affinity component appeared to show similar requirements. It is concluded that the glucose transport system in $S$. cerevisiae is regulated by a catabolite-inactivation process.
\end{abstract}

\section{INTRODUCTION}

Most enzymes in Saccharomyces cerevisiae are very stable, maintaining their catalytic activities for long periods under different metabolic conditions (Halvorson, 1958 $a, b$; Lagunas et al., 1982; López \& Gancedo, 1979). Sugar carriers behave exceptionally in this respect, in that a rapid and irreversible inactivation is observed upon inhibition of protein synthesis (Alonso \& Kotyk, 1978; Lagunas et al., 1982). This inactivation of the sugar transport systems is responsible for important metabolic events, such as a drastic decrease of fermentation in ammonium-starved cells (Lagunas et al., 1982), and is related to the occurrence of the Pasteur effect (Lagunas, 1979, 1981 ; Lagunas et al., 1982). Until recently it was believed that $S$. cerevisiae had only one transport system for glucose, with two different affinity constants depending on the presence or absence of oxygen (Serrano \& delaFuente, 1974). However, it is now known that this transport system consists of two components controlled differently: the high-affinity component is subject to catabolite repression (Bisson \& Fraenkel, 1984) and is influenced by the presence of hexose kinases (Bisson \& Fraenkel, $1983 a, b$ ), but neither of these mechanisms seems to control the low-affinity component.

The existence of these two components prompted the question whether both are subject to the irreversible inactivation observed during impairment of protein synthesis (Lagunas et al., 1982). This research attempts to clarify this point and to determine the characteristics of the inactivation. For this purpose the activity of the glucose transport system has been studied in yeast cells under different metabolic conditions using glucose and xylose as substrate.

\section{METHODS}

Reagents. Enzymes and nucleotides were from Sigma. $\mathrm{D}-\left[\mathrm{U}-{ }^{14} \mathrm{C}\right] \mathrm{Glucose}$ and $\mathrm{D}-\left[\mathrm{U}^{14} \mathrm{C}\right] \mathrm{xylose}$ were from Amersham. All other reagents were of analytical grade. 
Strains, media and culture conditions. Two strains of Saccharomyces cerevisiae were used: a wild-type, ATCC 42407 (used unless otherwise stated), and a triple mutant, BYS 232-14-23, deficient in endopeptidase B and carboxypeptidase $Y$ and S (Wolf \& Ehmann, 1981), provided by D. H. Wolf (Freiburg im Breisgau, FRG). The cells were grown aerobically in rich medium containing $0.3 \%(\mathrm{w} / \mathrm{v})$ yeast extract with $2 \%(\mathrm{w} / \mathrm{v})$ sugar (glucose, galactose or maltose) or $2 \%(\mathrm{v} / \mathrm{v})$ ethanol as the carbon source. Flasks $(2.5 \mathrm{l})$ containing $250 \mathrm{ml}$ medium and stoppered with cotton plugs were incubated at $30^{\circ} \mathrm{C}$ in a gyratory shaker at 250 r.p.m.

Conditions for ammonium starvation. Cells growing exponentially (about $1.5 \mathrm{mg}$ dry cells $\mathrm{ml}^{-1}$ ) were harvested by centrifugation, washed with the ammonium-free medium (Lagunas, 1976) and resuspended in this medium in the presence or absence of sugars or ethanol, as indicated in each experiment, to a cell density of about $0.5 \mathrm{mg} \mathrm{ml}^{-1}$. They were incubated aerobically at $30^{\circ} \mathrm{C}$ as described above. When ammonium starvation was induced in the presence of proteinase inhibitors, the following compounds were added to the ammonium-free medium at the final concentrations indicated: $1 \mathrm{~mm}$-phenylmethylsulphonyl fluoride, $100 \mu \mathrm{M}$-leupeptin, $10 \mu \mathrm{g}$ antimycin $\mathrm{ml}^{-1}, 10 \mu \mathrm{g}$ chymostatin $\mathrm{ml}^{-1}, 10 \mu \mathrm{g}$ pepstatin $\mathrm{ml}^{-1}, 1 \mathrm{~mm}-()$-phenanthroline, $5 \mu \mathrm{M}$-p-hydroxymercuribenzoate.

Treatment with iodoacetate. Yeast cells were harvested by centrifugation, washed with distilled water and resuspended in an equal volume of $0.5 \mathrm{~mm}$-sodium iodoacetate at $\mathrm{pH} 3.5$. After $5 \mathrm{~min}$ at $30^{\circ} \mathrm{C}$, the cells were harvested by filtration, washed twice with an equal volume of water and transferred to a medium as indicated in each experiment. After this treatment, fermentation and respiration of sugars were undetectable.

Cell growth. This was followed by measuring $\mathrm{OD}_{640}$ in a Hitachi spectrophotometer or by determination of the dry weight.

Total protein. This was determined as described by Jayamaran et al. (1966).

Sampling of the cells and determination of ATP. The rapid sampling method described by Sáez \& Lagunas (1976) was followed. ATP was determined by the spectrophotometric method described by Jaworek et al. (1974), in cell extracts obtained with perchloric acid in the presence of liquid nitrogen (Sáez \& Lagunas, 1976).

Activity of the glucose transport system. When D-[U-14 C]glucose was used as substrate, this activity was measured as described by Bisson \& Fraenkel $(1983 a)$. Uptake was initiated by addition of the labelled sugar $(0 \cdot 5-$ $\left.4 \mathrm{mCi} \mathrm{mmol}^{-1} ; 18 \cdot 5-148 \mathrm{MBq} \mathrm{mmol}^{-1}\right)$. After incubation at $30^{\circ} \mathrm{C}$ for $5 \mathrm{~s}, 10 \mathrm{ml}$ chilled $\left(4^{\circ} \mathrm{C}\right)$ water was added and the cells were collected on glass-fibre filters and washed with $10 \mathrm{ml}$ chilled water. When $\mathrm{D}-\left[\mathrm{U}-{ }^{14} \mathrm{C}\right] \mathrm{xylose}$ was used, the method described by Serrano \& delaFuente (1974) was followed. Uptake was initiated by addition of labelled sugar $\left(50 \mu \mathrm{Ci} \mathrm{mmol}^{-1} ; 1.85 \mathrm{MBq} \mathrm{mmol}^{-1}\right)$. After incubation for $1 \mathrm{~min}$ at $30^{\circ} \mathrm{C}, 10 \mathrm{ml}$ chilled water was added and the suspension was centrifuged at $3000 \mathrm{~g}$ for $1 \mathrm{~min}$. After decantation of the supernatant, the cells were suspended in $10 \mathrm{ml}$ chilled water, collected on glass-fibre filters and washed with an additional $10 \mathrm{ml}$ chilled water.

\section{RESULTS AND DISCUSSION}

\section{Both components of the glucose transport system are inactivated}

The biphasic kinetics of glucose uptake (Fig. 1a) confirmed previous results regarding the existence of two components of the glucose transport system (Bisson \& Fraenkel, 1983a). The kinetics indicated $K_{\mathrm{m}}$ values for glucose of about $1.5 \mathrm{~mm}$ and $35 \mathrm{~mm}$ respectively, in agreement with those reported by Bisson \& Fraenkel $\left(1983 a\right.$ ). The results also indicated that the $V_{\max }$ of the component of high $K_{\mathrm{m}}$ was about 10 times greater than the $V_{\max }$ of the component of low $K_{\mathrm{m}}$ (intersecting points of the respective straight lines with the ordinate axis).

To establish whether both components were inactivated upon inhibition of protein synthesis we studied their respective activities separately using $1 \mathrm{~mm}$ - or $50 \mathrm{~mm}$-glucose as substrate. At $1 \mathrm{~mm}$-glucose about $70 \%$ of the sugar taken up is transported by the high-affinity component, whereas at $50 \mathrm{~mm}$-glucose about $85 \%$ is transported by the low-affinity component. These values are calculated by substituting the kinetic constants of both components (Fig. $1 a$ ) in the Michaelis-Menten equation. The results (Fig. 2) indicated that the two components of the glucose transport system were inactivated similarly and that their inactivation paralleled the inactivation observed when $0 \cdot 2 \mathrm{M}$-xylose was used as substrate.

\section{Affinities of the two components of the glucose transport system for xylose}

The accuracy of the assay of the glucose transport system using $\mathrm{D}-\left[\mathrm{U}-{ }^{14} \mathrm{C}\right] \mathrm{glucose}$ as substrate is limited by the rapid catabolism of this sugar. This compels the use of short incubation periods (5s) and does not allow intensive washing of the cells (Bisson \& Fraenkel, 1983a). Under these experimental conditions as much as $70 \%$ of the total radioactivity measured is due to nonspecific adsorption of $\mathrm{D}-\left[\mathrm{U}-{ }^{14} \mathrm{C}\right]$ glucose to the filters and inaccurate results are obtained (note the large standard errors in Fig. 2). Experiments attempting to decrease these high blanks, e.g. 


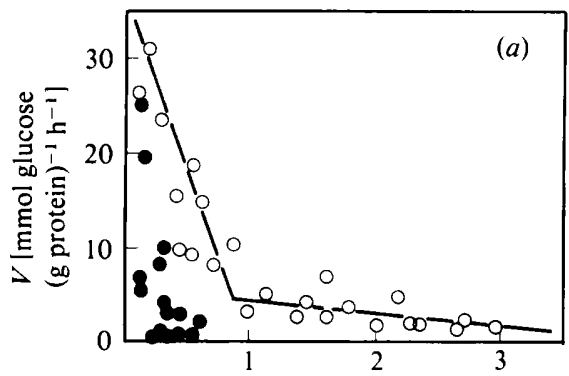

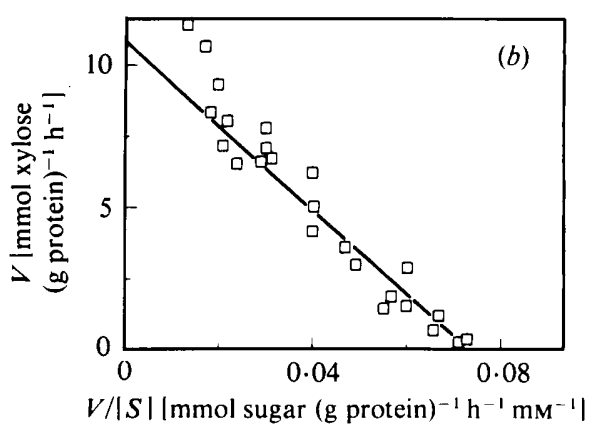

Fig, 1

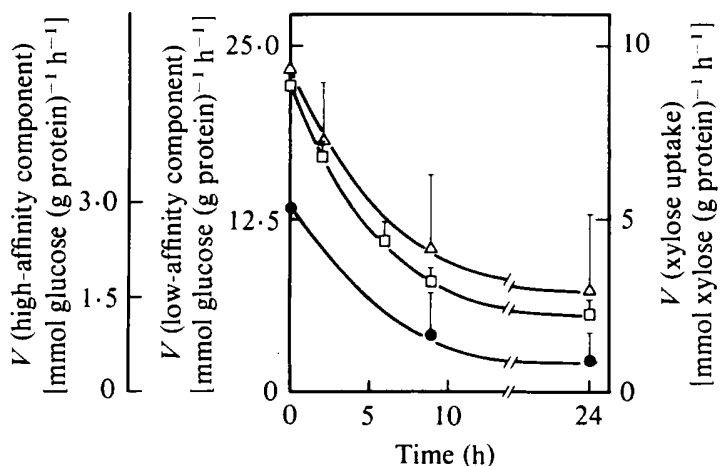

Fig. 2

Fig. 1. Kinetics of the glucose transport system using D-glucose and D-xylose as substrate. (a) Yeast cells were grown with $2 \%(w / v)$ glucose and harvested during exponential growth. Transport was measured using $\mathrm{D}-\left[\mathrm{U}-{ }^{14} \mathrm{C}\right]$ glucose at concentrations ranging from $0.2 \mathrm{~mm}$ to $0.1 \mathrm{M}$ in the absence $(\mathrm{O})$ and in the presence (O) of $1 \mathrm{M}$-D-xylose. (b) Cells grown and harvested as described above were used to measure transport using $\mathrm{D}-\left[\mathrm{U}-{ }^{4} \mathrm{C}\right] \mathrm{xylose}$ at concentrations ranging from $5 \mathrm{~mm}$ to $0 \cdot 8 \mathrm{M}$.

Fig. 2. Inactivation of the two components of the glucose transport system. Yeast cells were grown with glucose and harvested during exponential growth. They were transferred to ammonium-free medium containing $2 \%(\mathrm{w} / \mathrm{v})$ glucose and incubated at $30^{\circ} \mathrm{C}$. At the indicated times, sugar transport was measured using $1 \mathrm{mM}-\mathrm{D}-\left[\mathrm{U}-{ }^{1+} \mathrm{C}\right]$ glucose $\left(4 \mu \mathrm{Ci} \mu \mathrm{mol}^{-1}\right)$ (assay for the high-affinity component, $O$ ), $50 \mathrm{mM}-\mathrm{D}-\left[\mathrm{U}-{ }^{1}+\mathrm{C}\right] \mathrm{glucose}\left(1 \mu \mathrm{Ci} \mu \mathrm{mol}^{-1}\right)$ (assay for the low-affinity component, $\triangle$ ) and $0 \cdot 2 \mathrm{M}$-D-[U$\left.{ }^{14} \mathrm{C}\right]$ xylose $\left(125 \mu \mathrm{Ci} \mathrm{mmol}^{-1}\right)(\square)$. Mean values and standard errors of six experiments are shown.

by changing the amount of the cells or the specific radioactivity in the assays, were unsuccessful. To avoid these analytical limitations a non-metabolizable analogue of glucose should be used, and xylose, a non-phosphorylable sugar (Heredia et al., 1968; Sols et al., 1958) that allows better experimental conditions (Serrano \& delaFuente, 1974), has been generally employed (Alonso \& Kotyk, 1978; Cirillo, 1968; Lagunas et al., 1982; Serrano \& delaFuente, 1974). However, the discovery of the existence of two components of the glucose transport system posed the question whether xylose may be used to estimate the activity of both components.

To test whether xylose is a substrate for the two components, competitive inhibition of glucose uptake by xylose was studied (Fig. 1a). Two inhibition constants were obtained by applying the velocity equation in the presence of a competitive inhibitor. The difference between the two $K_{\mathrm{i}}$ values, $0.137 \pm 0.019 \mathrm{M}$ (SEM) for glucose concentrations of $0.2-2.0 \mathrm{mM}$, and $1.46 \pm 0.26 \mathrm{M}$ for glucose concentrations of $10-100 \mathrm{mM}$, was statistically significant $(t$ test $: P<0 \cdot 01$ ). Thus both components show affinity for xylose. However, in experiments where xylose uptake was measured, only the high-affinity component was detected and a $K_{\mathrm{m}}$ for xylose of about $0 \cdot 16 \mathrm{M}$ could be calculated (Fig. $1 b$ ). This value agrees with the $K_{\mathrm{i}}$ value obtained in the competition experiments (0.137 M) and with previous results (Serrano \& delaFuente, 1974). The failure to detect the low-affinity component in experiments on xylose uptake (Fig. $1 b$ ) may be accounted for by its high $K_{\mathrm{m}}$ value, which according to the competition experiments is about $1.5 \mathrm{M}$.

In routine assays, activity of the glucose transport system is measured using xylose at $0.2 \mathrm{M}$ 


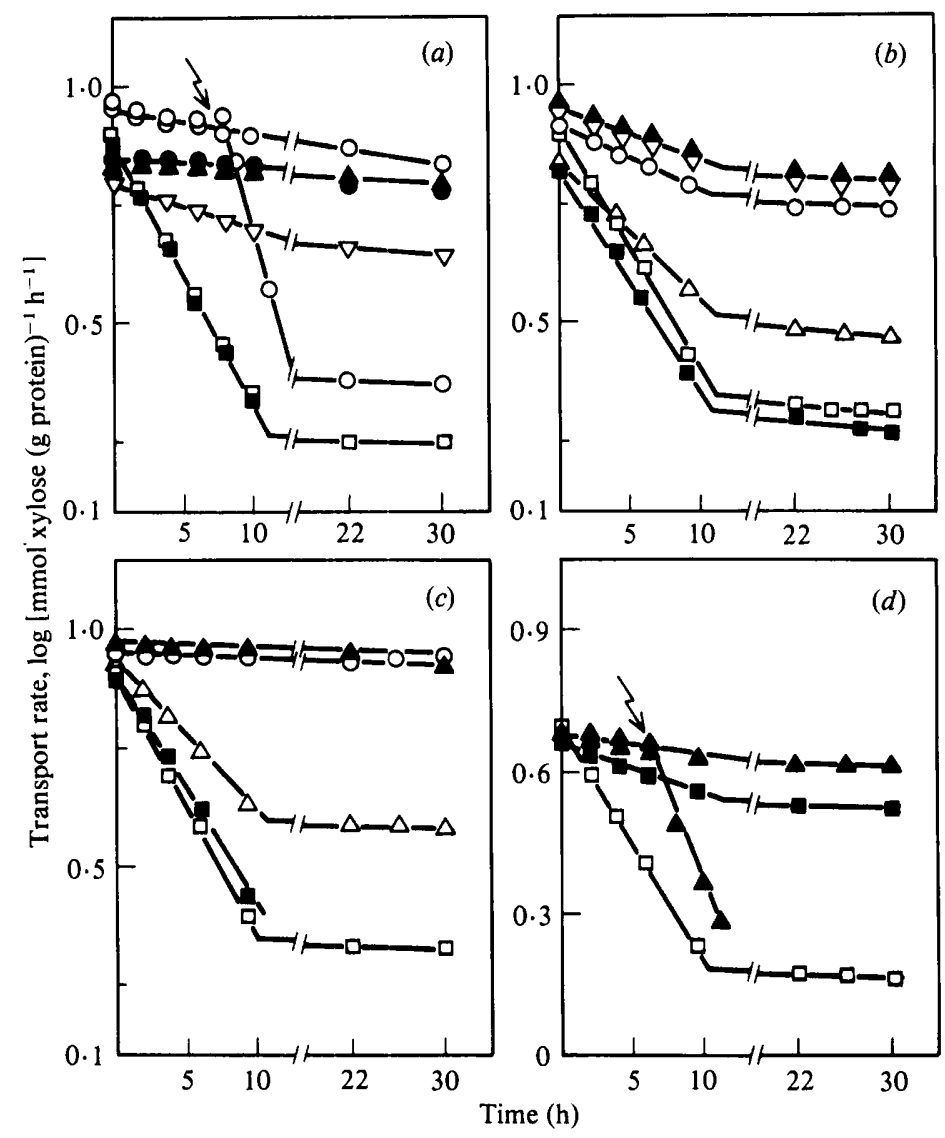

Fig. 3. Kinetics of the inactivation of the glucose transport system in yeast cells grown with different carbon sources. Yeast cells were grown with various carbon sources and harvested during exponential growth. They were then transferred to three times the initial volume of the media specified below, and after incubation at $30^{\circ} \mathrm{C}$ for the indicated times, were assayed for transport activity using $0 \cdot 2 \mathrm{M}-\mathrm{D}-[\mathrm{U}$ ${ }^{14} \mathrm{C}$ xylose $\left(125 \mu \mathrm{Ci} \mathrm{mmol}^{-1}\right)$. The results are the mean values of at least four experiments. The growth media contained the following carbon sources: $(a) 2 \%(\mathrm{w} / \mathrm{v})$ glucose, $(b) 2 \%(\mathrm{w} / \mathrm{v})$ galactose, $(c) 2 \%$ $(\mathrm{w} / \mathrm{v})$ maltose, $(d) 2 \%(\mathrm{v} / \mathrm{v})$ ethanol. Transfer media: $\bigcirc$, ammonium-free medium without carbon source; ammonium-free medium containing $2 \%$ glucose plus $8 \mathrm{~mm}$-arsenate; $\square$, ammonium-free medium containing $2 \%$ glucose; $\square$, complete medium containing the carbon source used for growth plus $10 \mu \mathrm{g}$ cycloheximide $\mathrm{ml}^{-1} ; \triangle$, ammonium-free medium containing the carbon source used for growth; $\boldsymbol{\Delta}$, ammonium-free medium containing $2 \%$ ethanol; $\nabla$, ammonium-free medium containing $2 \%$ glucose $(a)$ or galactose $(b)$, the cells having been previously treated with iodoacetate. The arrows indicate the addition of $2 \%$ glucose to part of the ammonium- and carbon-free culture in $(a)$ and to part of the ammonium-free culture containing ethanol in $(d)$.

concentration (Alonso \& Kotyk, 1978; Lagunas et al., 1982; Serrano \& delaFuente, 1974). On the assumption that both components transport xylose, as suggested by the competition experiments (Fig. $1 \mathrm{a}$ ), about $45 \%$ and $55 \%$ of the total xylose taken up would be transported by the high- and low-affinity component respectively. These values are obtained by applying the Michaelis-Menten equation assuming similar $V_{\max }$ values with xylose and glucose (Fig. $1 a$ ). It could be concluded on these assumptions that xylose may be used to estimate the activity of both components of the glucose transport system. However, the possibility suggested by the experiments shown in Fig. $1(b)$, that only the high-affinity component is detected using xylose as substrate, cannot be excluded. 
Kinetics of the inactivation of the glucose transport system in yeast cells adapted to glucose or ethanol

The inactivation of the glucose transport system was studied in detail with xylose as substrate. When protein synthesis in yeast cells growing with glucose was inhibited, either by addition of cycloheximide or by nitrogen starvation, an inactivation was observed that lasted for about $10 \mathrm{~h}$ and followed first-order kinetics. During this period a half-life of about $6 \mathrm{~h}$ could be calculated (Fig. $3 a$ ). By contrast, when protein synthesis was inhibited in yeast cells growing with ethanol, inactivation was not observed (Fig. $3 d$ ). This lack of inactivation could be due, in principle, to a lack in ethanol-adapted cells of the enzyme(s) responsible for the inactivation process. However, this possibility can be ruled out since addition of glucose to these cells produced a rapid inactivation of the transport system (Fig. $3 d$ ). These results suggest that the inactivation process requires the cells to be utilizing glucose or, probably, any other fermentable substrate. This hypothesis was tested by the experiments described below.

\section{Effect of ethanol and of different sugars on the kinetics of the inactivation}

The effect of ethanol and glucose catabolism on the kinetics of the inactivation was studied in yeast cells adapted to ethanol, glucose, galactose or maltose. The ability of these cells to catabolize ethanol in the absence of a nitrogen source was demonstrated by measuring their rate of respiration of this substrate. As expected from the catabolite repression effect of the sugars on the respiratory chain (Utter et al., 1968), the respiration rates were greater in cells grown with galactose or ethanol than in cells grown with glucose or maltose (Fig. 4).

When cells grown with any of the substrates were suspended in a medium containing ethanol as sole carbon source, inactivation of the glucose transport system did not occur (Fig. 3). However, when instead of ethanol, glucose was present, inactivation did occur, and half-lives of about $6 \mathrm{~h}$ were observed (Fig. 3). This inactivation was prevented when, in addition to sugars, inhibitors of catabolism such as iodoacetate or arsenate were present (Fig. 3a), or when a carbon source was absent (Fig. 3). To test the effect of galactose and maltose on the inactivation process, yeast cells adapted to respective sugars were used (Fig. $3 b, c$ ). In both cases the glucose transport system was inactivated in the presence of the sugars, and half-lives of about $10 \mathrm{~h}$ and $9 \mathrm{~h}$, respectively, were observed. The inactivation also disappeared in these cells upon treatment with iodoacetate or carbon starvation. These results strongly suggest that the inactivation of the glucose transport system requires the utilization by the cells of a sugar. They also indicate that of the sugars tested, glucose supports the inactivation most effectively.

Prevention of the inactivation by iodoacetate and arsenate could be due, in principle, to their effect on the energetic state of the cells. Indeed these compounds decreased the intracellular ATP content (Fig. 5a). According to this interpretation, the inactivation of the glucose transport system would be energy dependent. However, the lack of inactivation in ethanolconsuming cells cannot be ascribed to a deficient energetic state since their ATP content was similar to that of sugar-consuming cells (Fig. 5), in which inactivation was indeed observable. These results suggest that other metabolite(s), probably related to the occurrence of glycolysis, are actually involved in the inactivation process.

\section{Endopeptidase $B$ and carboxypeptidase $Y$ and $S$ are not involved in the inactivation}

The involvement of proteinases in specific inactivation of enzymes, continuous turnover of proteins, and many other proteolytic processes in yeast cells is well established (for a review see Wolf, 1982). To check whether proteolysis was responsible for inactivation of the glucose transport system we studied this inactivation in a mutant strain deficient in endopeptidase B and carboxypeptidase $\mathrm{Y}$ and $\mathrm{S}$, and in a wild-type strain after addition of proteinase inhibitors (see Methods). In both kinds of experiments normal rates of inactivation were observed (results not shown) indicating that neither endopeptidase $\mathrm{B}$ nor carboxypeptidase $\mathrm{Y}$ and $\mathrm{S}$ is involved in this process. However, the involvement of other proteinases is not ruled out by these experiments since proteinase inhibitors have not been shown to permeate the yeast plasma membrane. 


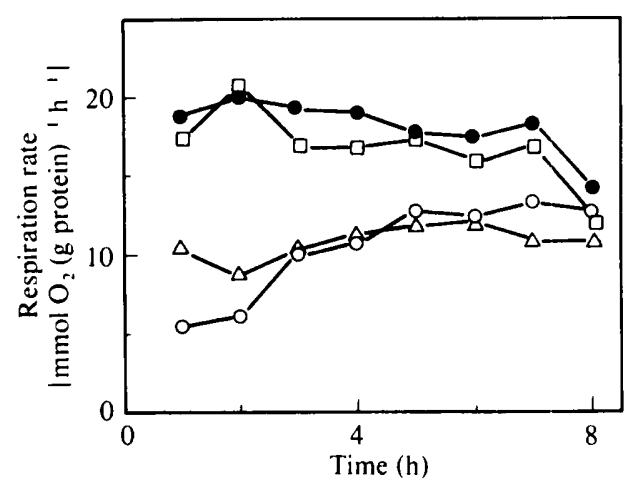

Fig. 4

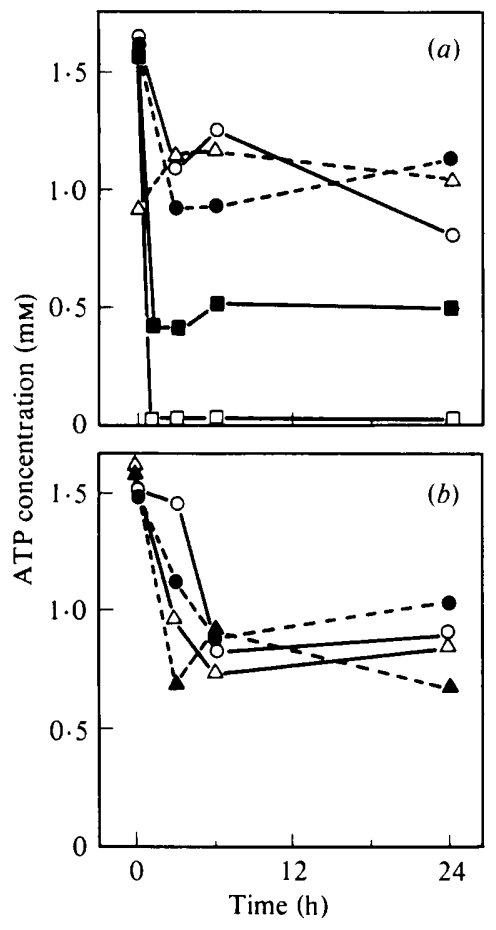

Fig. 5

Fig. 4. Respiration of ethanol by yeast cells grown with different carbon sources. Yeast cells were grown with $2 \%(w / v)$ glucose $(O)$, maltose $(\triangle)$, galactose $(\square)$ or ethanol $(\bigcirc)$ and harvested during exponential growth. They were transferred to ammonium-free medium containing $2 \%(\mathrm{v} / \mathrm{v})$ ethanol and the rates of respiration were measured (see Methods). Mean values of two experiments are shown.

Fig. 5. Concentration of ATP in yeast cells utilizing different carbon sources during ammonium starvation. (a) Yeast cells were grown with $2 \%(\mathrm{w} / \mathrm{v})$ glucose and harvested during exponential growth. They were transferred to three times the initial volume of ammonium-free media containing $2 \%$ glucose $(O), 2 \%$ ethanol (O), $2 \%$ glucose plus $8 \mathrm{~mm}$-arsenate $(\square)$, or $2 \%$ glucose, the cells having been previously treated with iodoacetate (see Methods) $(\square)$. Yeast cells grown with $2 \%(\mathrm{v} / \mathrm{v})$ ethanol and treated as above were transferred to ammonium-free medium containing $2 \%(w / v)$ glucose $(\triangle)$. After incubation at $30^{\circ} \mathrm{C}$, ATP was extracted and measured at the indicated times (see Methods). Mean values of two experiments are shown. (b) Yeast cells grown with $2 \%(w / v)$ maltose and treated as above were transferred to ammonium-free media containing $2 \%$ maltose $(\triangle)$ or $2 \%$ ethanol $(\boldsymbol{\Delta})$. Yeast cells grown with $2 \%(\mathrm{w} / \mathrm{v})$ galactose and treated as above were suspended in ammonium-free media containing $2 \%$ galactose $(\mathrm{O})$ or $2 \%$ ethanol $(O)$. After incubation at $30{ }^{\circ} \mathrm{C}$. ATP was extracted and measured as above. Mean values of two experiments are shown.

\section{General conclusions}

The results obtained demonstrate that both components of the glucose transport system of $S$. cerevisiae are inactivated. They also indicate that inactivation of the high-affinity component requires the utilization by the cells of a fermentable substrate. This conclusion derives from the following: (i) inactivation did not occur during carbon starvation; (ii) when a fermentable sugar was added inactivation began; (iii) when in addition to sugars, inhibitors of fermentation were added, inactivation was prevented; (iv) when a non-fermentable substrate was added instead of sugars, inactivation was also prevented. The inactivation of the low-affinity component appeared to show similar requirements. It is concluded that the glucose transport system in $S$. cerevisiae is subject to a sugar-induced inactivation, corresponding to the catabolite inactivation described by Holzer (1976). 
We are grateful to Dr D. H. Wolf for providing the triple mutant BYS 232-24-23, to E. Moreno for excellent technical assistance, and to Drs C. F. Heredia, C. Gancedo and I. Outschoorn for critical reading of this manuscript.

This work was supported by Comision Asesora para la Investigación Científica y Técnica. A.B. had a fellowship of Gobierno Vasco, Departamento de Universidades e Investigación.

\section{REFERENCES}

Alonso, A. \& Kotyk, A. (1978). Apparent half-lives of sugar transport proteins in Saccharomyces cererisiae. Folia microbiologica 23, 118-125.

Bisson, L. F. \& FraenKeL, D. G. (1983a). Involvement of kinases in glucose and fructose uptake by Saccharomyces cerevisiae. Proceedings of the National Academy of Sciences of the United States of America 80, 1730-1734.

Bisson, L. F. \& Fraenkel, D. G. (1983b). Transport of 6-deoxyglucose in Saccharomices cerevisiae. Journal of Bacteriology 155, 995-1000.

Bisson, L. F. \& Fraenkel, D. G. (1984). Expression of kinase-dependent glucose uptake in Saccharomyces cerevisiae. Journal of Bacteriology 159, 1013-1017.

Cirillo, V. P. (1968). Relationship between sugar structure and competition for the sugar transport system in baker's yeast. Journal of Bacteriology 95 , 603-611.

Halvorson, H. (1958a). Studies on protein and nucleic acid turnover in growing cultures of yeast. Biochimica et biophysica acta 27, 255-266.

Halvorson, H. (1958b). Intracellular protein and nucleic acid turnover in resting yeast cells. Biochimica et biophysica acta 27, 267-276.

Heredia, C. F., Sols, A. \& delaFuente, G. (1968). Specificity of the constitutive hexose transport in yeast. European Journal of Biochemistry 5, 321-329.

Holzer, H. (1976). Catabolite inactivation in yeast. Trends in Biochemical Sciences 1, 178-180.

JAWOREK, D., GRUBER, W. \& Bergmeyer, H. U. (1974). Determination of adenosine-5'-triphosphate with 3-phosphoglycerate kinase. In Methods of Enzymatic Analysis, 2nd edn, pp. 2097-2101. Edited by $\mathrm{H}$. U. Bergmeyer. New York \& London: Academic Press.

Jayamaran, J., Cotman, C., Mahler, H. M. \& Sharp, C. V. (1966). Biochemical correlation of respiratory deficiency. VII. Glucose repression. Archives of Biochemistry and Biophysics 116, 224-252.

LAGUNAS, R. (1976). Energy metabolism of Saccharomyces cerevisiae. Discrepancy between ATP balance and known metabolic functions. Biochimica et biophysica acta 440, 661-674.
LAGUNAS, R. (1979). Energetic irrelevance of aerobiosis for Saccharomyces cerevisiae growing on sugars. Molecular and Cellular Biochemistry 27, 139-146.

LaGunas, R. (1981). Is Saccharomyces cerevisiae a typical facultative anaerobe? Trends in Biochemical Sciences 6, 201-202.

lagunas, R., Dominguez, C., Busturia, A. \& Sáez, M. J. (1982). Mechanisms of appearance of the Pasteur effect in Saccharomyces cerevisiae: inactivation of the sugar transport systems. Journal of Bacteriology 152, 19-25.

López, S. \& Gancedo, J. M. (1979). Effect of metabolic conditions on protein turnover in yeast. Biochemical Journal 178, 769-776.

SáEz, M. J. \& LaGunas, R. (1976). Determination of intermediary metabolites in yeast. Critical examination of the effect of sampling conditions and recommendations for obtaining true levels. Molecular and Cellular Biochemistry 13, 73-77.

Serrano, R. \& DelaFuente, G. (1974). Regulatory properties of the constitutive hexose transport in Saccharomyces cerevisiae. Molecular and Cellular Biochemistry 5, 161-171.

Sols, A., DelaFuente, G., Villar-Palasí, C. \& AsEnSIO, C. (1958). Substrate specificity and some other properties of baker's yeast hexokinase. Biochimica et biophysica acta 30, 92-101.

UtTer, M. F., Duel, E. A. \& Bernofsky, C. (1968). Alteration in the respiratory enzymes of the mitochondria of growing and resting yeast. In Aspects of Yeast Metabolism, pp. 197-212. Edited by A. K. Mills \& H. A. Krebs. Oxford: Blackwell.

Wolf, D. H. \& Ehmann, C. (1981). Carboxypeptidase $\mathrm{S}$ and carboxypeptidase Y-deficient mutants of Saccharomyces cerevisiae. Journal of Bacteriology 147 , 418-426.

WolF, D. H. (1982). Proteinase action in vitro versus proteinase function in vivo: mutants shed light on intracellular proteolysis in yeast. Trends in Biochemical Sciences 7, 35-37. 